\title{
High density suburbs redevelopment and social housing retrofitting for cities regeneration
}

\author{
A. Boeri \& D. Longo \\ University of Bologna, DAPT, Faculty of Architecture of Cesena, Italy
}

\begin{abstract}
The suburbs of modern cities have become key elements in the scenarios of ever changing cities: once considered problem areas, they are now defined as important components for a general urban redevelopment in planning projects.

The issue of suburbs is today ever present in the processes of strategic urban planning: they are considered as areas of integrated transformation, ranging from the landscape and cultural heritage enhancement to buildings retrofitting interventions, up to an economical uplift and to an improvement of the infrastructural systems.

The most important Italian case studies and the conditions of the suburban areas in modern cities (in disrepair, or interested by upgrading processes) have identified some of the prevailing critical aspects of urban planning carried out to date.

This paper proposes the analysis of one case study, the Pilastro neighborhood, a significant example of a social housing high density settlement, located in the outskirts of Bologna (IT). This district is an imposing housing estate, chosen for its representation of the social housing heritage in Italy.

This paper highlights the technical, functional and social factors the level of quality of the settlement depends on, as well as the phenomena of social unease it resulted in. It also highlights some elements that may be considered as an obstacle against improvement measures.

Architectural and social quality are the two elements to be aimed for, for a correct strategy of redevelopment and regeneration of the Pilastro neighborhood. Keywords: social housing, renovation, sustainability, quality strategies.
\end{abstract}




\section{Introduction}

Suburbs, once considered critical areas, are now thought of as key elements in the urban redevelopment of towns by the planning instruments in force. Strategic planning and urban redevelopment consider them as areas of integrated transformation, ranging from the landscape and cultural heritage enhancement to buildings retrofitting interventions, up to an economical uplifting and an improvement of the existing infrastructure systems.

Nowadays, the redevelopment of suburban areas is not limited to just their physical or environmental recovery; it also consists in their overall regeneration, through actions that have an impact not only on the architectural, urban, technological and economical fields, but also on the social and relational ones [1].

\section{Social housing heritage in Italy}

According to a report drafted by Censis, in collaboration with Federcasa, the public social housing heritage in Italy, managed by Aziende Casa, is just under 940,000 residential units, 768,000 of which are rented. The public stock is less than $4 \%$ of the total housing currently in use (ISTAT-CGP 2001); however it amounts to about $18.8 \%$ of the total rental housing available. Due to its small quantity, the share of social housing does not significantly affect the market and, actually, it is currently falling due to the sale of public housing. Since the 1980s, the availability of public housing has been reduced by $90 \%$, especially after the abolition of the Gescal system (1995-1998) which, up to then, provided guaranteed funds.

Social housing could be defined as an ensemble of activities, initiatives and instruments implemented by public bodies or by private operators, to reduce the social disadvantages of individuals or groups who cannot meet their housing needs (for financial reasons or for lack of suitable offers), allowing them access to residential units considered safe and fit for human habitation [2].

The elements that define social housing are in particular:

- The strong social characteristics that identify it as a financial service of public interest, aimed at safeguarding social cohesion;

- The broad social target of reference, consisting overall of that segment of population who, while not in a state of poverty, which would automatically grant them the right to public housing, cannot afford to pay the rent asked by the market.

Today, the situation of social housing in Italy is very fragmented, due to limited funding or emergency interventions: the national policy long standing weakness on the matter of housing did not allow the establishment of a defined scenario where each single region could rule to meet the needs of its own territory.

The heritage built from the end of the Second World War onwards is now in a state of decay and needs interventions more or less significant, ranging from a simple restoration of the outside and inside finishing, to a replacement of 
obsolete or worn out systems, from a replacement of the sanitary fittings, to the adaptation of the layout and size of rooms to meet the new requirements rising from the changes in the composition of the family or from new lifestyles.

It is not by chance that since the end of the 1980s building activity has mainly concerned the redevelopment of existing stock in the measure of $60 \%$. For the first time, interventions on the built stock exceeded the ones related to new constructions, leading to a significant change of direction for the building sector.

\section{Decay factors}

The current social housing stock, built mainly during the 1970 s, is in a state of decay, both from a technical and social point of view. The factors for the demise of our suburbs are multiple; however it is difficult to pinpoint the primary cause of decay.

Naturally, the problems related to the physical condition and to the management of the buildings are among the main causes.

Public opinion tends to ascribe the main responsibility to the planning choices, especially for those neighborhoods built during the 1970s and 80s; symbols of the modern city: high-density settlements, urban impact and large buildings unsuitable for the context [3].
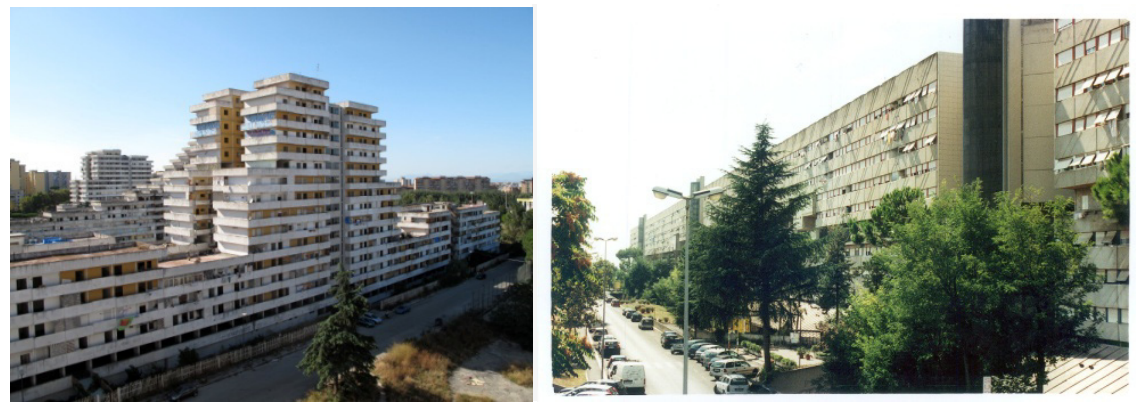

Figure 2: Vele in Naples and Corviale in Rome: symbols of Italian social housing decay.

The construction and urban quality of the building intervention carried out during the 1960s, 70s and 80s, considered lacking by public opinion, found support in the academic world that identified strong connotations with the Unitè d'Abitation of Le Corbusier in Marseille and with the modern idea of the cityneighborhood, however ascribing the responsibility of its non-perfect realization to the bad quality of construction and, afterwards, even to the absolute lack of maintenance combined with the failure of realizing all the aspects included in the original project.

Special examples are the neighborhoods of Vele in Naples, Zen in Palermo and Corviale in Rome, where besides the problems relating to architectural decay (due to the almost total lack of maintenance on the buildings) there are serious problems relating to social degradation, with a high rate of school drop-outs, 
micro-criminality and mafia infiltration. Despite the numerous media reportages and the commitment of schools and religious and voluntary bodies, the situation in these neighborhoods is still not acceptable.

In the instance of Naples, a non-realization of common areas every six floors of a building, a lack of pedestrian paths, playing areas for children, parking areas and bus stops, have deeply affected the quality of social life of those residential districts, forcefully positioned in one of the most problematic neighborhoods of Naples, Scampia.

Similarly in Rome, in the neighborhood of Corviale (General Coordinator: M. Fiorentino with Federico Gorio, Pietro M. Lugli and others) built during the 1970s, where many families living there are squatters.

The original idea was to build a self-sufficient city within the city. Designed as a huge residential unit, it houses, in a single building $1 \mathrm{~km}$ long, dwellings for about 8,500 residents. A building of such dimensions, too long for many people, almost a kilometer of solid concrete, with the flaw of having never been completed. Some equipment foreseen by the project was never realized, and an entire floor intended for commercial and business use was abandoned, and later used by squatters who turned it into dwellings. The operating conditions were totally neglected.

The design of these areas was strictly based on the operating mechanisms, on the capability of the public to manage the services integrated with the residences and on the integration of the residents' relationship with each other.

The management model, strongly connected with public bodies, faltered even before starting: the services structures were abandoned, soon after turning into an element of degradation.

From the moment this structure was entered on the Ministry list of "ecomonsters", the debate on Corviale became ever more heated, reaching the idea that parts of the Palazzone could be demolished in order to obtain more controllable areas.

Less significant situations, in terms of the buildings' physical decay, can be found in neighborhoods such as Forte Quezzi in Genova, Gallaratese in Milan and Pillastro in Bologna. However, even these last ones, even if in a more limited way, have experienced a condition of high decay and phenomena of social exclusion that have led to a process of "ghetto" creation, whose impact has been felt up to today.

In Italy, the situation of the existing residential stock is rather unsatisfactory, also in terms of energy consumption. The level of energy demand for winter heating - the common benchmark - is extremely high. Therefore, the requalification actions aim at ensuring balanced conditions in accordance with the different climatic conditions [4].

\section{The Pilastro neighborhood}

As part of the "Program for Scientific Research of Relevant National Interest" (PRIN), in 2008, the MIUR "Ministry of Education and University and Research" co-funded the research "Renovation, regeneration and valorisation of 
social housing settlements built in the suburban areas in the second half of last century", carried out by a team of researchers of the Faculty of Architecture of the University of Bologna (Faculty of Cesena ), together with researchers of the University of Ferrara (national coordinator Prof. Roberto Di Giulio), University IUAV of Venice, the Polytechnic of Turin, University "G. D'Annunzio" of Chieti-Pescara.

The research unit of the University of Bologna investigated the case study of the Pilastro neighborhood, an important settlement of public housing located in Bologna, the capital city of the Emilia Romagna region.

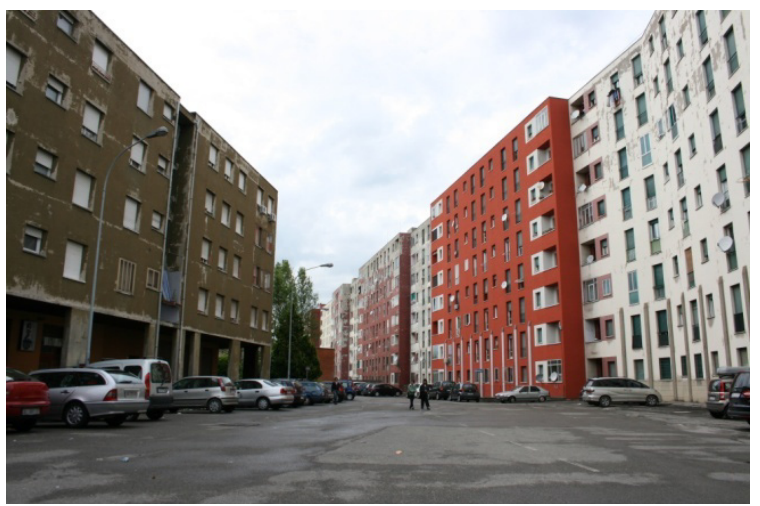

Figure 3: The Pilastro neighborhood in Bologna - Italy.

The Pilastro district was chosen by our research unit for both its dimension and symbolism, as well as for its representative image of social housing heritage in Italy. Pilastro, with its 7,500 residents (about 3,000 less than during the 1970s), is an important settlement of public housing located in the San Donato district in Bologna. It was developed during a period ranging from the end of the 1950 s up to the middle $80 \mathrm{~s}$ and this is the reason why the main development stages of social housing building are represented here, with examples of different typological, technological and constructive experimentations that characterized its evolution.

The concentration of residents belonging to the weaker social class and the isolation they experienced in this neighborhood, perceived as a dormitory, led to a series of social problems in a short time.

The tunnel system, which in Italy has been applied in a limited way and only during the middle $70 \mathrm{~s}$, combines some of the most relevant solutions applied in large public housing estates. This system rigidity, repetition and non-variance are the conditions that led to significant difficulties to the end users who had to adapt to residential units not suitable for their needs, and neither them nor the management bodies had the opportunity of making improvements to the interior layout or to a re-dimensioning of the residential units.

The restraint of unsuitable spaces encouraged misappropriation of outer common areas, such as the balconies, at Pilastro or Corviale, the back lanes and walkways at Vele. 


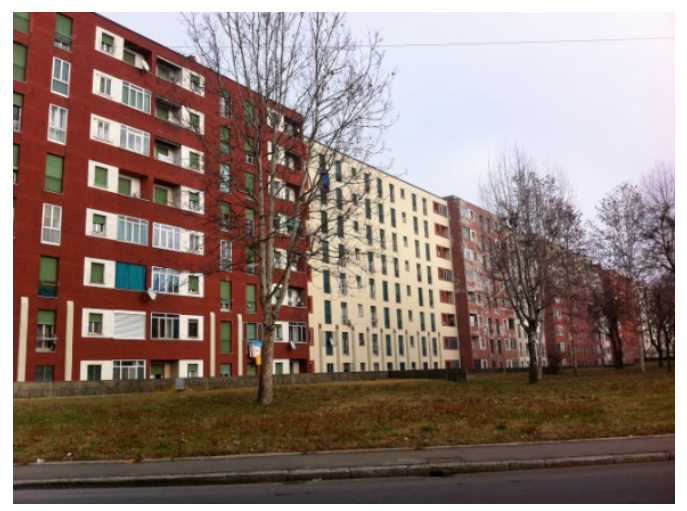

Figure 4: $\quad$ Some already retrofitted buildings in the Pilastro neighborhood.

A second aspect that had a negative impact on large settlements and that can be found in most Italian suburban areas built during the baby-boom years is the mono-functionality.

However, the cause of this negative connotation almost never lies with the projects, which actually foresaw, in most cases, structures for commercial use and social activities as a support to the estate. The realization of said services was carried out a long time after the residential units were finished, if ever.

The differences between Pilastro and other public neighborhoods, that are still in a state of disrepair and for which the only solution for their regeneration seems to be their demolition, are mainly two: a monitoring by the neighborhood residents and a constant commitment on the part of the public authorities and the management body in not abandoning it to its destiny, despite the chronic lack of funds for maintenance and improvement works.

The analysis clearly highlights the two most critical aspects, today related to the architectural and social quality. The first one is increasingly compromised by the obsolescence and disrepairs of the building, due to its age, lack of maintenance and poor construction quality. The changing needs of new users can not be met in full in residential units of the old type that are under or wrongly used. These buildings' appearance, ever repetitive and not appealing to the eye, even if at the time it was the result of careful planning, is now associated with the idea of degradation.

The strong monotony of their façades, which in the case of "Virgolone" are identical and uninterrupted for $700 \mathrm{~m}$, even if as a result of well intended projects, is today felt by the residents as negative branding and, with no other gelling elements, does not contribute to create an "urban image" that could generate a sense of belonging.

The poor quality of the exterior finishing and the state of disrepair they are in are a clear statement of the current difficulties ACER Bologna, the managing body of the public housing stock in Bologna, is going through in meeting the necessary maintenance works. 


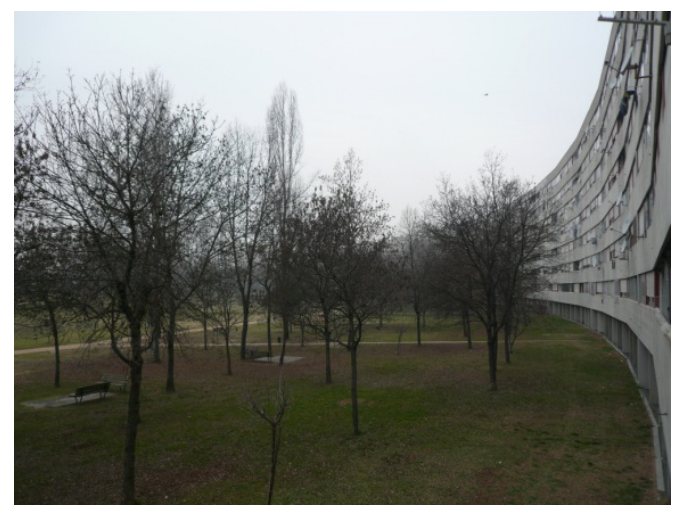

Figure 5: Virgolone building in the Pilastro neighborhood, Bologna.

A further strong weakness of the Pilastro estate is its high energy needs, with its connotations on the tenants, who have to meet the relevant bills out of their own pockets.

\subsection{Strategies of intervention}

Our research identified some strategies of intervention, derived both from the analysis of aspects identified as peculiar and potentially influential for development and planning, and from the analysis of a selection of requalification case studies carried out both in Italy and in Europe.

The study on the reference building, Virgolone, was completed focusing on an intervention for a morphological and energy improvement, by optimizing the use of the spaces and by the application of integrated renewable energy sources. The efficiency in terms of a reduction in energy needs was verified through a simulation model of the building behavior.

The scheduling and the priority order of the interventions played an essential role in the efficiency of the requalification strategies and were developed according to the degree of impact on the objectives to be achieved [5].

In the requalification project of Virgolone the thermal envelope was redefined, that is, we selected which parts of the building were to be included within the climatically controlled area.

As regards Virgolone, the requalification project involved a careful study of the different available options. The priorities of interventions were established in relation to the degree of impact on the improvement of indoor comfort and energy performance, to obtain the thermal balance, that is, the set of heat exchanges between the building interior and exterior, therefore, identifying the sections and components which were the main cause of heat dispersions to gradually intervene on them. Bearing in mind that requalification interventions distributed on more than one technical element tend to better balance the environmental conditions by generating a higher degree of evenness and wellbeing, a series of strategies, applicable based on their complexity and on the funds available, were identified. 


\subsection{The energy analysis as fundamental factor}

The energy analysis was carried out on the main reference building, Virgolone: its envelope and plants installation were analyzed, by comparing and cross referencing the current data of energy consumption stated in the bills paid by the residents with the results of an energy assessment performed with a software UNI/TS compliant; a model of the energy behavior of the entire building was generated, allowing through a variation of the different factors to assess which technological components were to be modified in order to improve its energy behavior and therefore determining design specifications for an energy requalification intervention. The energy need datum resulted from the software assessment $\left(101.10 \mathrm{kWh} / \mathrm{m}^{2} \mathrm{y}\right)$, was $4.9 \%$ higher than the one $\left(96.20 \mathrm{kWh} / \mathrm{m}^{2} \mathrm{y}\right)$ stated on the energy bills. The small gap between the two data above allow to state that the simulation model of the energy behavior generated for Virgolone is reliable and was used to formulate intervention scenarios of wider connotation, aimed to reducing energy consumption and increasing the residents' indoor comfort.

\subsection{The three classes of interventions on the reference-building}

After the analysis of the critical aspects and of the opportunities that characterize the Virgolone building and the whole area of Pilastro, possible steps of intervention were identified, taking into consideration different aspects (technical, structural, energetic, social). These stages of intervention aim to achieving several objectives related to quality and comfort, depending on available funds and feasibility.

The following three classes of interventions were identified:

- the first consisted of the improvement of the envelope for high energy performance;

- the second class of interventions concerned the residential units and aimed at improving the indoor layout and the adaptation of the rooms to the actual needs of modern families;

- the third aimed at creating a functional mix, introducing satellites volumes on the ground floor next to the Virgolone building and in the front facing park.

In particular, the first two types of intervention do not provide for a change in volume of the building and are applicable at low cost, without any particular disruption for the residents.

\subsubsection{STEP 1: interventions on the envelope}

The first step consists of an intervention to improve the performance of the building envelope. For this reason, in the particular case of the Virgolone building, it is possible, in the first instance, to apply a thermal coat to comply with the building energy performance that the law requires and replace the windows with others of superior thermal performance without changing the configuration of the existing façades or the size of the glazed surfaces. 
As an alternative, and always in relation to the building of reference, it is possible to replace the façade panels on the north and south sides with prefabricated elements characterized by better energy performance.

This intervention, due to both its difficulty in implementation and the necessary temporary evacuation of the residents during the work, allows, at the same time, a redevelopment of their interiors to be carried out (by moving back or forwards some parts of the envelope, integrating balconies and winter gardens, carrying out adjustments to the dimension of the indoor spaces to bring them up to standard, ...) with a consequent significant improvement in the quality of living spaces.
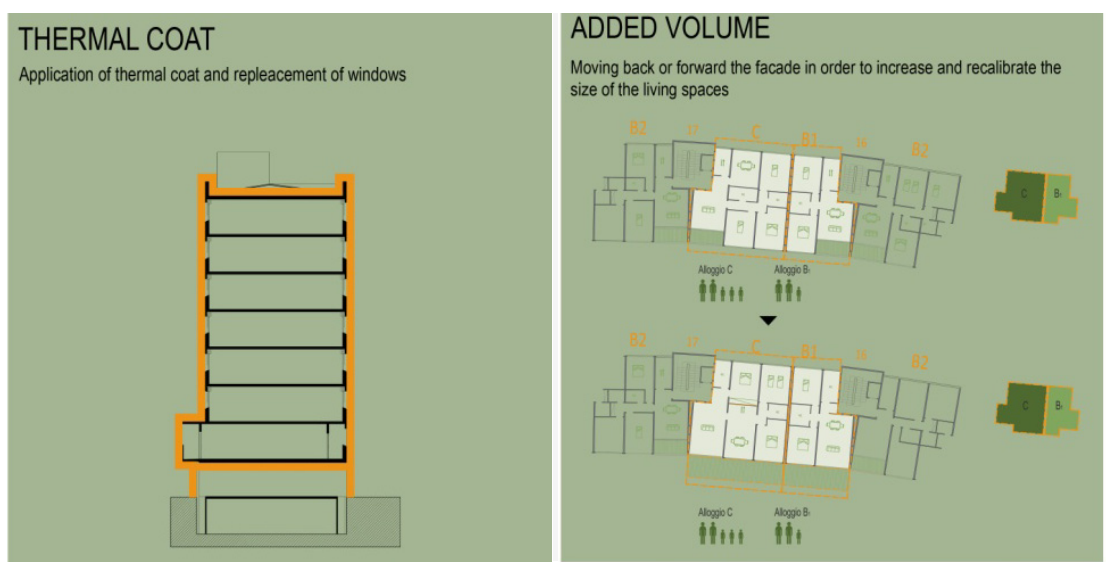

Figure 6: Interventions on the envelope and on the living spaces.

Furthermore, at this stage, it is possible to redefine the openings (considering the rigid division of the façade due to the concrete tunnel structure), that can be extended on the south side, to optimize the level of lighting comfort, and which can be reduced on the north side, to reduce heat loss during the winter.

\subsubsection{STEP 2: Interventions on residential units}

Proceeding according to the two directions of intervention, the low-cost one and the most comprehensive and incisive, but more invasive one, even in the second step it is possible to refurbish the Pilastro neighborhood in different ways, depending on the starting conditions and the objectives to pursue.

The first action, defined "volume zero", consists of the redevelopment of the residential units, in terms of indoor layout, without substantial changes in the building, whose envelope has been already improved during the previous step. Amongst the interventions: the correct sizing of under-standard indoor spaces, the definition of layout solutions suitable for different types of families to meet different needs in case of a change of tenancy and the design of multi-functional spaces. 


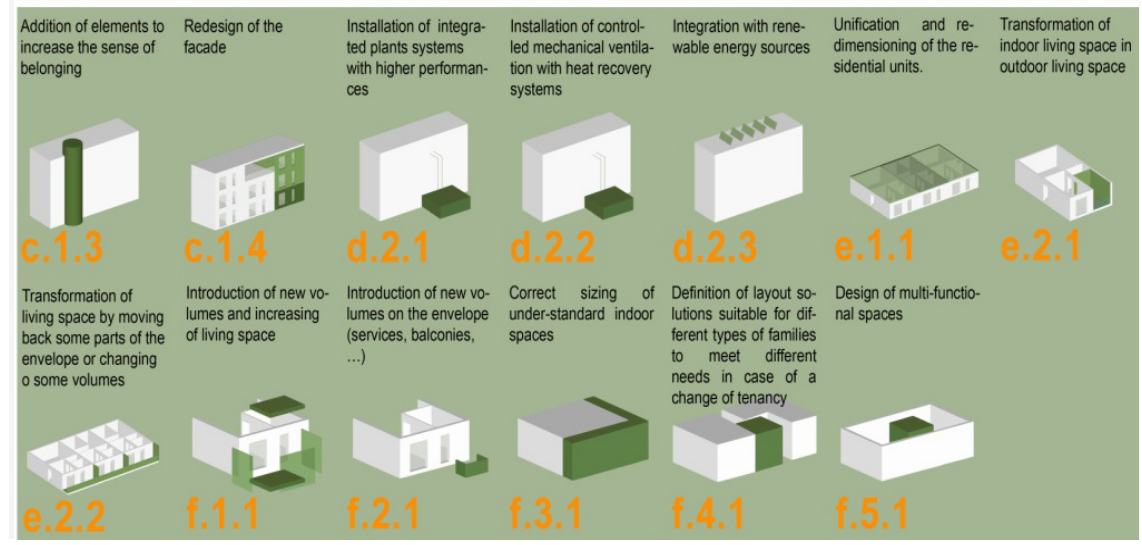

Figure 7: Schemes of "added volumes" in order to increase outdoor and living spaces.

The ZERO VOLUME intervention involves intervention strategies aimed at reducing the operating costs of the district, through the installation of integrated plants systems with higher performance, controlled mechanical ventilation with heat recovery systems in the units and integration with renewable energy sources.

The intervention on the units consists of introducing new volumes, characteristic elements of recognition in order to reduce the sense of disorientation of the residents, redefining the façade in a more modern way.

This strategy, which can be defined as "added volume", is characterized by moving the façade back or forwards, in order to increase outdoor spaces and recalibrate the size of the living spaces. The addition of volumes on the façade helps to expand and redefine the units, both through the realization of new living spaces, winter-gardens and solar greenhouses, and an increase in the service related spaces and balconies.

\subsubsection{STEP 3: Functional mix}

As regards the social and architectural redevelopment of the Pilastro neighborhood some possible strategies were identified:

- an implementation of the mix of functions in the neighborhood, introducing strategic activities and services;

- an improvement in the relation between the Virgolone building and the surrounding area, by increasing the number of pedestrian and cycle paths connecting the residential area with the park and with the other services of the district;

- a requalification of the community open spaces intended for collective use. 


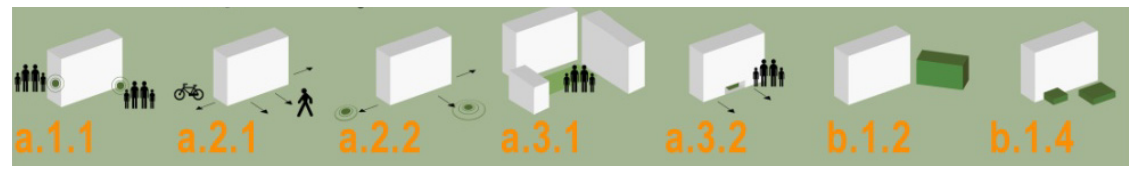

Figure 8: Introduction of strategic activities, squares, services buildings for neighborhood regeneration.

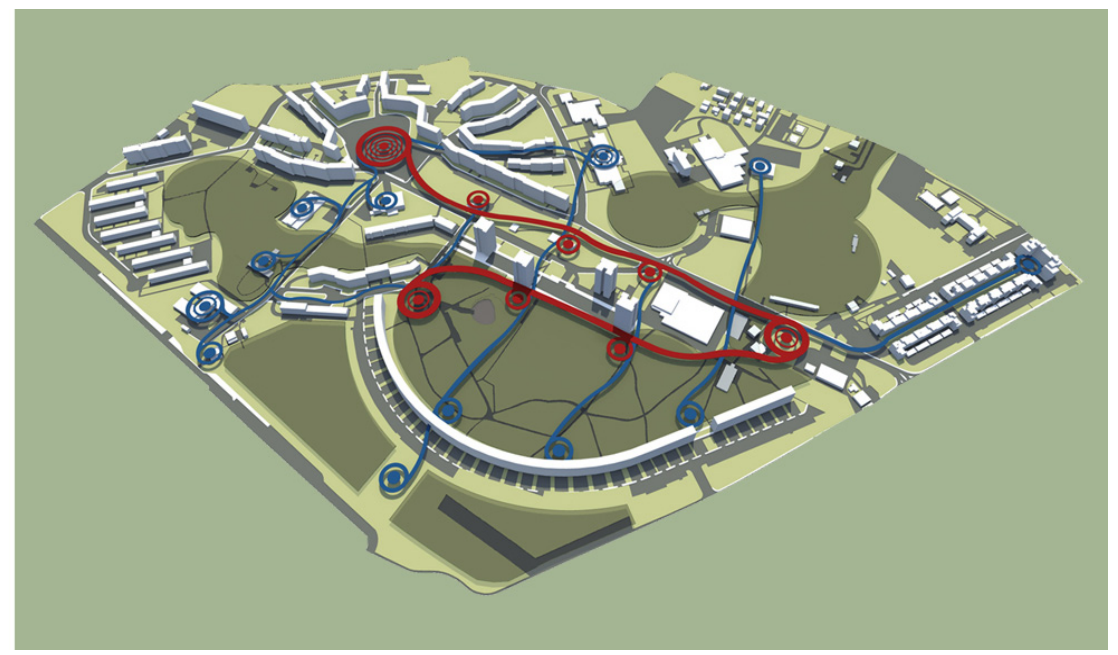

Figure 9: Implementation of functions in the Pilastro neighborhood, introducing strategic activities and services.

\section{Conclusions}

The approaches to the retrofit project are complex and require architectural (in accordance with the building's characteristics), technological, economical and energy assessments, and therefore they also imply the need to refer to competent subjects and experiences of a different nature.

Flexible programs, new and old housing typologies, the use of traditional and innovative materials and technologies, as well as interesting financial solutions are the key to ensure an economically accessible social housing, characterized by a good level of architectural quality and compliant with the health and safety and environmental regulations, in terms of energy-saving requirements.

In this context, new housing interventions and retrofitting projects may be the chance to also control the transformation of the city and its territory, applying technologies and typologies capable of meeting the new forms of living and the pressing needs of environmental and economical sustainability of the interventions.

The rationalization of the existing social housing, its functional and morphological redevelopment, the increase in its financial value and the 
reduction of operating costs can give rise to a set of actions useful in meeting at least part of the growing demand.

The need to define interventions aimed at redeveloping this housing stock was identified and consequently favored by a set of planning tools supported by our National Government (Urban Recovery Programs, Urban Regeneration Programs, Urban Regeneration and Sustainable Development Programs, District Contracts I and II).

Since the 1990s, these planning tools have provided testing and management programs for regeneration of suburban areas. Sustainable development and requalification of degraded settlements are also considered priority targets by the European Commission (Green Paper on Urban Development and Urban Community Programs 1 and 2) and, even if with different approaches, many European countries are implementing measures aimed at regenerating social housing, paying particular attention to energy efficiency and environmental sustainability.

\section{References}

[1] AA., Una nuova stagione per l'housing, Be-Ma, Milano, 2009.

[2] CECODHAS, White EB, Housing Europe 2007- Review of Social, Cooperative and Public Housing in the 27 EU Member State, 2007.

[3] Grecchi M. (edited by), Il recupero delle periferie urbane. Da emergenza a risorsa strategica per la rivitalizzazione delle metropoli, Maggioli, Rimini, 2008.

[4] Di Giulio R. (edited by), Improving the Quality of Suburban Building Stock, COST Action TU0701, University of Malta, 2010.

[5] Sassi P., Strategies for sustainable architecture, Taylor \& Francis, New York, 2006. 